・论坛・ 中国国家公园试点专题

\title{
钱江源-百山祖国家公园试点经验与发展方向
}

申小莉 ${ }^{\circledR}$, 李晟 ${ }^{\circledR 2}$, 马克平 ${ }^{\circledR 1}$

1. 中国科学院植物研究所植被与环境变化国家重点实验室, 北京 100093; 2. 北京大学生命科学学院, 北京 100871

申小莉, 李晟, 马克平 (2021) 钱江源-百山祖国家公园试点经验与发展方向. 生物多样性, 29, 315-318. doi: 10.17520/biods.2021079. Shen XL, Li S, Ma KP (2021) Experiences of and suggestions for the development of the Qianjiangyuan-Baishanzu National Park pilot. Biodiversity Science, 29, 315-318. doi: 10.17520/biods.2021079.

\section{Experiences of and suggestions for the development of the Qianjiangyuan- Baishanzu National Park pilot}

Xiaoli Shen ${ }^{(1 *}$, Sheng $\mathrm{Li}^{\left({ }^{2} 2\right.}$, Keping Ma ${ }^{(\mathbb{D} 1}$

1 State Key Laboratory of Vegetation and Environmental Change, Institute of Botany, Chinese Academy of Sciences, Beijing 100093 2 School of Life Sciences, Peking University, Beijing 100871

钱江源-百山祖国家公园试点位于浙江省境内, 包括衢州市钱江源和丽水市百山祖两个片区。其中, 钱江源片区试点于 2016年启动, 同年6月《钱江源国 家公园体制试点区试点实施方案》获国家发展和改 革委员会批复。2017年3月, 钱江源国家公园党工 委、管委会经浙江省机构编制委员会办公室批复设 立，与开化县委县政府实行“两块牌子、一套班子” 的“政区合一”管理模式。2017年10月，浙江省政府 同意发布实施《钱江源国家公园体制试点区总体规 划(2016-2025)》。2019年7月, 浙江省委整合钱江源 国家公园党工委、管委会, 新设立钱江源国家公园 管理局, 由省政府垂直管理, 纳入省一级财政预算 单位, 委托省林业局代管。2020年1月, 国家林业和 草原局(国家公园管理局)批准“一园两区”的方案, 同意设立丽水市百山祖片区。2020年8月，《钱江源 一百山祖国家公园总体规划(2020-2025)》通过专家 评审, 由浙江省政府正式批复实施。

\section{1 关键经验}

1.1 探索了东部经济发达地区建立国家公园的途 径与模式

受地理气候、人为活动与开发历史等多种因素
影响, 我国华东、华南地区比西部地区经济发达、 人口密集、土地利用强度高。在人类活动的长期作 用下, 这些地区的原始生态系统受破坏与干扰较为 严重, 自然景观破碎, 动物群落结构不完整, 大型 食肉和食草动物缺失(Tilson et al, 2004; Cao et al, 2019)。因此, 在我国面积广大的东部经济发达地区, 国家公园如何实现生态系统原真性与完整性保护 的目标, 是首批国家公园体制试点需要深入探索和 解决的问题。

钱江源一百山祖国家公园试点实施过程中, 积 极探索实践, 发展出“一园两区”和“跨区共建”的保 护模式。体制试点首先在钱江源片区开展, 以原古 田山国家级自然保护区、钱江源国家森林公园、钱 江源省级风景名胜区为基础, 规划总面积约 $252 \mathrm{~km}^{2}$; 后续在浙江省政府的协调下, 新增百山祖 片区，包括原凤阳山-百山祖国家级自然保护区、庆 元大鳃国家级水产种质资源保护区、景宁英川香炉 山次生阔叶林自然保护小区、庆元班岱后南方铁杉 保护小区，规划总面积 $505 \mathrm{~km}^{2}$ 。“一园两区”的模式 将试点区的面积扩展至758 $\mathrm{km}^{2}$ 。同时, 地处浙赣皖 三省交界白际山脉的钱江源片区, 在试点过程中积 极开展“跨区共建”。与毗邻的江西、安徽所辖3镇7 
村, 以及安徽休宁岭南省级自然保护区签订合作保 护协议, 共建联合保护站和巡护队伍, 实现省际毗 邻镇村合作保护模式全覆盖。钱江源片区所在的浙 江省开化县与毗邻的江西德兴、雊源, 安徽休宁 4 地政法系统共同签署《开化宣言》, 摸索建立跨区 联合保护的司法协作机制。

钱江源-百山祖国家公园试点的以上措施与尝 试, 为我国东部经济发达地区如何规划和建设国家 公园, 促进对典型生态系统类型与生态过程的原真 性与完整性保护, 提供了非常有价值的经验与示范。

\section{2 探索出集体林地地役权改革方案}

在我国华东、华南地区，集体所有自然资源占 比高, 与西部地区国有土地占绝对优势的格局形成 明显反差(王宇飞等, 2019)。在钱江源片区和百山祖 片区，集体土地的面积占比分别为 $80.70 \%$ 与 88.51\%。在此背景下, 国家公园如何有效实现对区 内集体自然资源的统一管理，是体制试点中需要摸 索的关键问题。

钱江源片区于 2018年率先开展区内的集体林 地地役权改革, 进行了有效的尝试, 取得了良好的 效果和示范效应。在国家公园管理局和地方政府的 共同指导下, 在不改变集体所有的森林、林木、林 地权属的前提下，由农户或村民小组自行委托村民 委员会管理，再由村民代表大会集体表决形成决议， 将集体所有土地的管理权统一授权给钱江源国家 公园管理局(王宇飞等, 2019; 藏振华等, 2020)。 2018年2月, 经浙江省政府批准，钱江源片区的集 体林地地役权补偿金纳入省财政预算。2020年6月, 管理局正式启动承包地地役权改革试点, 在不改变 土地权属的条件下, 通过设立权利义务和正负面清 单，规范个人在承包地上的行为; 同时，村民享有 承包地地役权补偿。2020年9月, 开化县自然资源与 规划局为钱江源片区颁发2,753本“林地保护地役权 证”, 生态补偿费惠及2.6万余人, 从法律层面为集 体林地保护地役权提供保障。

钱江源-百山祖国家公园钱江源片区的地役权 改革实践探索, 为我国南方集体林区推进以国家公 园为主体的自然保护地体系建设积累了经验, 得到 了高度关注和广泛认可, 成为国家公园试点中集体 资源有效管理与保护的典型案例。

\section{3 以科研、监测支撑规划和管理}

钱江源-百山祖国家公园试点过程中, 高度重
视针对区内自然资源与生物多样性的科学研究与 科学监测, 将研究与监测成果作为国家公园保护的 重要基础。公园管理局与中国科学院植物研究所、 中国科学院动物研究所、浙江大学、北京大学、中 国林业科学研究院、浙江师范大学等科研机构合作, 依托钱江源森林生物多样性国家野外科学观测研 究站, 对区内代表性的中亚热带常绿阔叶林生态系 统和黑麘 (Muntiacus crinifrons)、白颈长尾雉 (Syrmaticus ellioti)等旗舰物种开展了广泛、深入的 研究与监测(Chen et al, 2019; 任鹏等, 2019; 余建 平等, 2019a)。

在试点期间，钱江源片区建立起覆盖全域的野 生动物红外相机监测网络, 并结合跨区共建辐射到 周边毗邻的江西、安徽部分地区(余建平等, 2019b; 申小莉等, 2020)。结合卫星遥感、近地面遥感、地 面样方、全自动声学监测等新技术(李杰等, 2019; 赵芗等, 2020), 建立起全域的、动植物综合的“天空 地一体化”监测平台, 对区内生物多样性组成与动 态变化开展长期、深入的研究与监测。基于监测平 台所获取的大量数据与信息, 深入开展了生物多样 性形成和维持机制(例如Chen et al, 2019)、生物多样 性与生态系统功能关系(例如Liu et al, 2018)等方面 的研究，并支撑了国家公园的生物多样性编目(例 如李通等，2019; 钱海源等，2019; 余建平等, 2019b)、空间规划(例如李杰等，2019; 余建平等, 2019a)、保护成效评估(例如申小莉等, 2020)、生态 系统服务价值评估(孙孝平等, 2019)等工作。2019年 9月，中国政府通过外交部向联合国可持续发展峰 会递交《地球大数据支撑可持续发展目标报告》，钱 江源国家公园生物多样性监测成为示范案例之一 (https://www.fmprc.gov.cn/mfa_eng/topics_665678/2 030kcxfzyc/P020190924800116340503.pdf)。

钱江源-百山祖国家公园试点过程中，充分体 现了科研、监测在国家公园建设、规划、决策与宣 传中的重要作用与价值, 为推进我国国家公园和保 护地的科学化管理与科学监测体系的构建提供了 示范。

\section{发展方向探讨}

2.1 探索实现国家公园原真性、完整性保护的标 准，制定长期的保护管理目标与计划

如何设定国家公园的最小面积或适宜面积，在 
满足生态系统原真性、完整性保护与管理可操作性 之间取得平衡, 是当前特别是东部地区的国家公园 体制试点中, 需要深入研究和探讨解决的重要问题。

原生植被占比低且呈破碎化分布, 大型食肉动 物和食草动物缺失, 人口密度高和人为活动压力大 是我国华东、华南地区生态系统共有的特征(Tilson et al, 2004; Cao et al, 2019)。钱江源-百山祖国家公 园试点通过 “一园两区”和 “跨区共建” 的模式, 对提 升生态系统的原真性、完整性保护进行了积极的尝 试。其中钱江源片区为探索跨区共建的范围和区域, 在更大的区域尺度(开化县全域和江西、安徽毗邻地 区)开展了生物多样性本底调查。建议公园管理局从 理论研究和管理实践两个方面进一步深入探索:

(1)通过基于生态学的研究确定实现生态系统 完整性、原真性保护的面积需求。现有“一园两区” 的保护地范围能够有效维持中亚热带常绿阔叶林 生态系统现存的动植物群落的组成和功能。根据钱 江源片区大范围调查数据, 可以进一步优化国家公 园空间布局方案。同时, 考虑到该区域现阶段生态 系统的特点, 动物群落营养级不完整将会影响生态 系统长久的稳定性。建议将恢复和重建生物群落结 构完整性(例如促进豹 Cuon alpinus、水鹿 Rusa unicolor等大型食肉动物和食草动物野生种群的恢 复或重建, Li et al, 2020)作为国家公园远期(10-20 年)保护管理的目标, 通过扩大保护地范围、重引入 关键物种、建立廊道和恢复退化生境等多种途径, 为大型动物的回归创造适宜栖息地, 以此为目标确 定国家公园长期建设的面积需求。

(2)在管理实践方面, 以理论研究结果为指导, 在充分考虑社会和经济发展的前提下, 制定国家公 园远期的保护管理目标与计划, 在未来分步骤分阶 段地实施。特别地, 在跨行政区界(例如县界、地市 界、省界)的情况下, 需要积极探索因地制宜的联合 保护途径, 寻求政策和保护管理机制的保障和支 持。尤其是跨省界的协调已经超出了单个国家公园 和地方政府的责任与能力, 需要中央政府及国家部 委层面主持, 制定或修订相应的法律法规, 出台对 应的政策与管理办法, 协调做好跨行政区界的共建 共管。

\section{2 以国家公园建设为契机, 促进生态保护主流} 化, 推动建立社会经济绿色发展的新模式

钱江源-百山祖国家公园钱江源片区涉及 4 个
乡镇 21 个行政村 9,744 村民, 百山祖片区涉及 10 个 乡镇33个行政村6,240村民。在生态保护优先的前提 下，如何实现为区内和周边村民创收，带动乡村的繁 荣和地方经济的发展是国家公园建设的重要议题。

为此, 钱江源片区开展了国家公园小镇规划、生 态产品价值研究; 通过地役权补偿、购买服务等方式 引导社区村民的生产生活方式向更为环保的方向转 变, 以加快生态产品价值的实现; 打造钱江源国家 公园集体商标, 提高农林产品和文化旅游产品的溢 价能力; 开化县委提出“建设社会主义现代化国家公 园城市” 的目标。建议国家公园管理局和地方人民政 府以国家公园的建设为契机, 进一步推动生态保护 主流化, 建立“两山”理念转化路径的样本, 探索社会 经济绿色发展的新模式。具体建议包括: (1)优化地区 生态保护和经济发展的空间布局, 为国家公园的长 远发展(例如实现重引入大型食肉动物重建生物群落 完整性、开展廊道建设加强栖息地连通性、开展生 态恢复提升钱塘江上游森林的水土保持能力等长远 目标)预留空间。(2)编制生态产品清单, 建立生态产 品价值核算体系, 开展跨界生态补偿示范, 并以此 建立国家公园资金来源的补充机制; 建立国家公园 生态产品品牌标准和准入机制, 加强品牌建设, 探 索生态产品价值实现机制; 以国家公园为依托, 加 强面向社区居民和游客的自然教育, 提升社会公众 对高质量自然环境和生活品质的需求。

总之, 钱江源一百山祖国家公园作为我国东部 地区的国家公园, 其面积受到现存自然资源量和人 口分布的限制。尽管现阶段规划能够满足当前生态 保护的需求, 但相比历史基线或者相对维持生态系 统长远可持续发展的需求而言, 国家公园仍有扩大 保护面积的需求。因此, 在保护残存的原生植被及 动植物群落的前提下, 恢复受破坏的生境, 依靠重 引入等手段重建生物群落的完整性, 提升其生态系 统功能应当成为钱江源-百山祖国家公园保护管理 工作的长期目标。在此背景下, 为国家公园的长远 发展预留空间, 平衡保护和发展的矛盾, 建立社会 经济环境齐头并进的可持续发展模式, 是国家公园 可持续发展的前提条件, 也是地方经济可持续发展 的重要保障。如何跳出现有物理空间范围的制约, 着眼于更大时空尺度的发展, 并最终推动地区社会 经济发展的转型, 是我国现阶段生态文明建设对钱 江源一百山祖国家公园试点提出的更高要求。 
致谢: 感谢钱江源国家公园管理局提供大量基础材 料与信息。感谢汪长林、余建平等参与讨论并提供 宝贵的意见与建议。

\section{ORCID}

申小莉 (D) https://orcid.org/0000-0003-2749-1121

李軞 (D) https://orcid.org/0000-0001-7200-9539

马克平 (1D https://orcid.org/0000-0001-9112-5340

\section{参考文献}

Cao Y, Carver S, Yang R (2019) Mapping wilderness in China: Comparing and integrating Boolean and WLC approaches. Landscape and Urban Planning, 192, 103636.

Chen L, Swenson NG, Ji N, Mi X, Ren H, Guo L, Ma K (2019) Differential soil fungus accumulation and density dependence of trees in a subtropical forest. Science, 366, 124-128.

Li J, Li WY, Fu J, Gao J, Yang L, He WH (2019) Using low-altitude UAV remote sensing to identify national park functional zoning boundary: A case study in Qianjiangyuan National Park pilot. Biodiversity Science, 27, 42-50. (in Chinese with English abstract) [李杰, 李巍岳, 付晶, 高峻, 杨蕾, 何苇航 (2019) 基于近低空遥感技术的国家公园 功能分区边界识别: 以钱江源国家公园体制试点区为例. 生物多样性, 27, 42-50.]

Li S, McShea WJ, Wang DJ, Gu XD, Zhang XF, Zhang L, Shen XL (2020) Retreat of large carnivores across the giant panda distribution range. Nature Ecology \& Evolution, 4, 1327-1331.

Li T, Li JN, Wei YL (2019) Species diversity and distribution of wood-decaying fungi in Gutianshan National Nature Reserve. Biodiversity Science, 27, 81-87. (in Chinese with English abstract) [李通, 李俊凝, 魏玉莲 (2019) 古田山 国家级自然保护区木腐真菌物种多样性及分布. 生物多 样性, 27, 81-87.]

Liu X, Trogisch S, He J, Niklaus PA, Bruelheide H, Tang Z, Erfmeier A, Scherer-Lorenzen M, Pietsch KA, Yang B, Kühn P, Scholten T, Huang Y, Wang C, Staab M, Leppert KN, Wirth C, Schmid B, Ma K (2018) Tree species richness increases ecosystem carbon storage in subtropical forests. Proceedings of the Royal Society B: Biological Sciences, 285, 20181240.

Qian HY, Yu JP, Shen XL, Ding P, Li S (2019) Diversity and composition of birds in the Qianjiangyuan National Park pilot. Biodiversity Science, 27, 76-80. (in Chinese with English abstract) [钱海源, 余建平, 申小莉, 丁平, 李晟 (2019) 钱江源国家公园体制试点区乌类多样性与区系组 成. 生物多样性, 27, 76-80.]

Ren P, Yu JP, Chen XN, Shen XL, Song X, Zhang TT, Yu YQ, Ding P (2019) Seasonal variation in the distribution of Elliot's pheasant (Syrmaticus ellioti) in Gutianshan National Nature Reserve. Biodiversity Science, 27, 13-23. (in Chinese with English abstract) [任鹏, 余建平, 陈小南, 申 小莉, 宋淲, 张田田, 余永泉, 丁平 (2019) 古田山国家 级自然保护区白颈长尾雉的分布格局及其季节变化. 生 物多样性, 27, 13-23.]

Shen XL, Yu JP, Li S, Xiao HY, Chen XN, Chen SW, Liu MZ,
Ma KP (2020) Progress overview of the camera-trapping monitoring platform for the Qianjiangyuan National Park, Zhejiang Province. Biodiversity Science, 28, 1110-1114. (in Chinese with English abstract) [申小莉, 余建平, 李晟, 肖 慧芸, 陈小南, 陈声文, 刘鸣章, 马克平 (2020) 钱江源 国家公园红外相机监测平台进展概述. 生物多样性, 28, 1110-1114.]

Sun XP, Li S, Yu JP, Fang YJ, Zhang YL, Cao MC (2019) Evaluation of ecosystem service value based on land use scenarios: A case study of Qianjiangyuan National Park pilot. Biodiversity Science, 27, 51-63. (in Chinese with English abstract) [孙孝平, 李双, 余建平, 方彦君, 张银 龙, 曹铭昌 (2019) 基于土地利用变化情景的生态系统 服务价值评估：以钱江源国家公园体制试点区为例. 生 物多样性, 27, 51-63.]

Tilson R, Hu DF, Muntifering J, Nyhus PJ (2004) Dramatic decline of wild South China tigers: Field survey of priority tiger reserves. Oryx, 38, 40-47.

Wang YF, Su HQ, Zhao XR, Su Y, Luo M (2019) Conservation easement-inspired adaptive management methods for natural protected areas: A case study on Qianjiangyuan National Park pilot. Biodiversity Science, 27, 88-96. (in Chinese with English abstract) [王宇飞, 苏红巧, 赵金荃荵，苏杨，罗敏 (2019) 基于保护地役权的自然保护 地适应性管理方法探讨：以钱江源国家公园体制试点区 为例. 生物多样性, 27, 88-96.]

Yu JP, Shen YY, Song XY, Chen XN, Li S, Shen XL (2019a) Evaluating the effectiveness of functional zones for black muntjac (Muntiacus crinifrons) protection in Qianjiangyuan National Park pilot site. Biodiversity Science, 27, 5-12. (in Chinese with English abstract) [余建平, 申云逸, 宋小友, 陈小南, 李晟, 申小莉 (2019a) 钱江源国家公园体制试 点区功能分区对黑鹿保护的有效性评估. 生物多样性, 27, 5-12.]

Yu JP, Wang JY, Xiao HY, Chen XN, Chen SW, Li S, Shen XL (2019b) Camera-trapping survey of mammalian and avian biodiversity in Qianjiangyuan National Park, Zhejiang Province. Biodiversity Science, 27, 1339-1344. (in Chinese with English abstract) [余建平, 王江月, 肖慧芸, 陈小南, 陈声文, 李晟, 申小莉 (2019b) 利用红外相机公里网格 调查钱江源国家公园的兽类及鸟类多样性. 生物多样性, 27, 1339-1344.]

Zang ZH, Zhang D, Wang N, Du A, Kong LQ, Xu WH, Ouyang ZY (2020) Experiences, achievement, problems and recommendations of the first batch of China's national park system pilots. Acta Ecologica Sinica, 40, 8839-8850. (in Chinese with English abstract) [㶓振华, 张多, 王楠, 杜傲, 孔令桥, 徐卫华, 欧阳志云 (2020) 中国首批国家公园体 制试点的经验与成效、问题与建议. 生态学报, 40 , 8839-8850.]

Zhao Y, Shen XL, Li S, Zhang YY, Peng RH, Ma KP (2020) Progress and outlook for soundscape ecology. Biodiversity Science, 28, 806-820. (in Chinese with English abstract) [赵 莹, 申小莉, 李晟, 张雁云, 彭任华, 马克平 (2020) 声 景生态学研究进展和展望. 生物多样性, 28, 806-820.]

(责任编委：徐卫华 责任编辑：问文杰) 